\title{
Old and new determinants in the regulation of energy expenditure
}

\author{
A.P. Russell, and J.P. Giacobino \\ Department of Medical Biochemistry, University Medical Center, Geneva, Switzerland
}

\begin{abstract}
Bw gain is controlled by energy intake on one hand and expenditure on the other. The components of energy expenditure are basal metabolism, exercise induced thermogenesis and adaptive
\end{abstract}

\section{UNCOUPLING PROTEIN-1 (UCP1)}

In rodents, brown adipose tissue (BAT) is an important site of adaptive thermogenesis. Cold exposure has for long been known to induce, via stimulation of the sympathetic nervous system, an increase in BAT thermogenesis referred to as adaptive cold-induced thermogenesis (CIT), (1). Furthermore, it has been observed that voluntary overeating induced in rats by the administration of a palatable, so-called "cafeteria" diet also induced an increase in BAT thermogenesis which was called adaptive diet-induced thermogenesis (DIT) (2).

The main producer of heat in BAT is the uncoupling protein-1 (UCP1). This mitochondria inner membrane protein uncouples oxidative phosphorylation by dissipating the proton gradient generated by the re-oxidation of $\mathrm{NADH} \mathrm{H}^{+}$in the respiratory chain. The UCP1-mediated proton transport requires the presence of fatty acids and is specifically inhibited by purine di-and triphosphate nucleotides (3). The consequence of UCP1 activity is a decrease in the amount of ATP formed by the ATP synthase and energy dissipation as heat.

UCP1 knockout mice were generated and they were unable to maintain their body temperature upon cold exposure but did not become obese (4). These data confirmed the importance of UCP1 in

Key-words: $\beta_{3}$-adrenoceptor, uncoupling protein, energy expenditure, obesity.

Correspondence: Prof. J.P. Giacobino, Département de Biochimie Médicale, Centre médical universitaire, 1, rue Michel-Servet, 1211 Genève 4, Switzerland.

E-mail: Jean-Paul.Giacobino@medecine.unige.ch

Accepted 11 June, 2002 thermogenesis. In this short review we shall discuss the main determinants of adaptive thermogenesis. (J. Endocrinol. Invest. 25: 862-866, 2002)

${ }^{\oplus}$ 2002, Editrice Kurtis

CIT and suggested that, in UCP1 knockout mice, alternative mechanisms for maintaining body mass which could not protect against the cold were turned on.

In humans, BAT is present in newborn babies and decreases in 4-6 months after birth $(5,6)$. It is therefore generally believed that there is no UCP1 in human adults.

\section{THE $\beta_{3}$-ADRENOCEPTOR - UCP1 AXIS}

The family of the $\beta$-adrenoceptors were considered to consist of $\beta_{1}$ - and $\beta$-2-subtypes until 1989 when a third subtype was cloned (7). This third subtype called the $\beta_{3}$-adrenoceptor was found to be the predominant $\beta$-subtype in rodent BAT and white adipose tissue (WAT) $(8,9)$. When the BAT sympathetic nervous system activity is increased by cold exposure or overfeeding, the stimulatory effect on UCP1 activity and expression is therefore mediated essentially by the $\beta_{3}$-adrenoceptor (9). Therefore, the $\beta_{3}$-adrenoceptor-UCP1-axis is a major determinant of rodent adaptive thermogenesis.

The $\beta_{3}$-adrenoceptor was found to be down-regulated in obese $\mathrm{fa} / \mathrm{fa}$ Zucker rat BAT and WAT (8) and in obese ob/ob mouse adipose tissues compared to lean animals (10).

In $\beta_{3}$-adrenoceptor knockout mice, the capacity to adapt to a cold environment was fully preserved, but there was an increase in fat deposition under basal conditions and in response to a high fat diet (11). These data confirmed the importance of the $\beta_{3^{-}}$adrenoceptor in DIT and suggested that, in the $\beta_{3^{-}}$ adrenoceptor knockout mice, alternative mechanisms for maintaining body temperature were turned on. In rodents, cold exposure was found to recruit mul- 
tilocular cells expressing UCP1 in WAT (12). The effect of cold was mimicked by administration of the $\beta_{3}$-adrenoceptor agonist CL316'249 (13-16). The precursors of the brown adipocyte-like cells in WAT could be brown preadipocytes expressing the $\beta_{3}$ adrenoceptor or, as recently hypothesized, mature white adipocytes undergoing a transdifferentiation (17). We showed that the increase in UCP1 expression in the WAT induced by cold-acclimation was totally blunted in C57BL/6 $\beta_{3}$-adrenoceptor knockout mice. These results suggest that brown adipocytelike cell recruitment in the WAT is specifically controlled by the $\beta_{3}$-adrenoceptor (submitted).

In humans, the $\beta_{3}$-adrenoceptor is expressed in newborn baby BAT, although at a relatively lower level in comparison to the $\beta_{1} / \beta_{2}$-subtypes than in rodent BAT (18) and the question of its existence or not in WAT is controversial. No, or only a very low expression of $\beta_{3}$-adrenoceptor mRNA could be detected in various human WAT depots (9). A role of the $\beta_{3}$-adrenoceptor in the control of lipolysis in WAT has also been difficult to prove. Among $\beta_{3}$ agonists known to stimulate lipolysis in rodent fat cells, only the $\beta_{1} / \beta_{2}$-adrenoceptor antagonist and $\beta_{3}$-adrenoceptor agonist CGP 12177 was found to exert a lipolytic action in isolated human white adipocytes $(19,20)$. These observations, which supported the existence of an active $\beta_{3}$-adrenoceptor in human WAT, should now be reevaluated since CGP 12177 has recently been shown to behave as an agonist of a modified form of the $\beta_{1}$-adrenoceptor (21). New derivatives have recently been reported to display a $\beta_{1} / \beta_{2}$-adrenoceptor antagonistinsensitive lipolytic effect in isolated human white adipocytes. These results were interpreted as indicating that there is a $\beta_{3}$-adrenoceptor-mediated lipolytic response in human white adipocytes (22). Human genetic studies are of great importance for the evaluation of the biological role of a gene of interest in vivo. In 1995, a missense mutation in codon 64 of the $\beta_{3}$-adrenoceptor gene (Trp64Arg) was described which seemed to be responsible for features of insulin resistance and for a tendency to gain weight (23-25). In a recent review analyzing more than 100 published articles, Shuldiner et al. (26) concluded, based mostly on meta-analyses and functional studies, that the $\beta_{3}$-adrenoceptor has the perfect profile of an obesity-susceptibility gene. The $\beta_{3}$-adrenoceptor - UCP1 axis is a target of leptin. It has been shown that this adipocyte-derived hormone via stimulation of the sympathetic nervous system increases BAT UCP1 expression and thermogenesis (27-29).

The $\beta_{3}$-adrenoceptor - UCP1 axis would be a good target for anti-obesity drugs. If brown preadipo- cytes expressing the $\beta_{3}$-adrenoceptor are indeed present in human WAT, $\beta_{3}$-adrenoceptor agonists with a high affinity for these receptors might, by inducing the recruitment of brown adipocyte-like cells in the WAT depots, favor body energy expenditure.

\section{UNCOUPLING PROTEIN-3 (UCP3)}

In 1997, two novel members of the mitochondrial carrier family were discovered $(30,31)$. Based on their amino acid sequence identities with UCP1, they were called UCP2 and UCP3. UCP2 was expressed in most tissues studied and UCP3 mainly in skeletal muscle. An interesting feature of these novel uncoupling proteins was their high level of expression in human tissue $(30,31)$. Therefore, UCP3 might be an important determinant in the regulation of energy expenditure in humans. We will focus on UCP3 in this section.

UCP3 has been shown in heterologous yeast and mammalian cell expression systems to decrease mitochondrial membrane potential, and to increase whole cell basal $\mathrm{O} 2$ consumption and mitochondria State 4 respiration. This was considered a demonstration that UCP3 was an uncoupling protein (32-34). The most convincing demonstration, however, of the uncoupling activity of UCP3 is the recent finding that UCP3 reconstituted into proteoliposomes in the presence of coenzyme $\mathrm{Q}$ and fatty acids mediates a $\mathrm{H}^{+}$transport that is fully sensitive to purine nucleotides (35). The UCP3-induced uncoupling of oxidative phosphorylation observed in yeast models was recently re-evaluated and shown to be insensitive to the known activators or inhibitors of this protein, i.e. fatty acids or purine nucleotides, respectively (36). This suggests that the uncoupling observed in yeast mitochondria was an artifact. Good transfected cell models for the study of UCP3 putative uncoupling activity are therefore still lacking.

It was observed that fasting, a condition under which energy sparing should have priority, induced a large increase in muscle UCP3 mRNA expression (37). This observation of the so-called "fasting paradox" raised important questions to the function of UCP3 and even suggested that it would not behave as an uncoupling protein in vivo. The controversy has now reached a point where an attempt to put together the various theories seems important. We will first present the hypotheses concerning the biological role of UCP3. Then, we will discuss the possibility that UCP3, if it is not thermoregulatory, would nevertheless be thermogenic in vivo.

The hypothesis that UCP3 would be a thermogenic protein seemed to be supported by the observa- 
tion that transgenic mice overexpressing UCP3 in their skeletal muscle, despite the fact that they were hyperphagic, weighed less than their wild type controls. In the mitochondria isolated from these transgenic mice decreased membrane potential and respiratory control and an increased state 4 respiration compared to wild type mice mitochondria were observed (38). However, this uncoupling of mitochondrial oxidative phosphorylation was recently shown not to be inhibited by guanosine diphosphate (GDP), suggesting that it was an artifact of transgenic expression (39).

It is well established that a low rate of electron flow in the respiratory chain associated with a high proton gradient across the mitochondria membrane, like in state 4 respiration, increases mitochondria reactive oxygen species (ROS) production (40). Therefore, it was postulated that the UCP3 function would be, by mildly uncoupling oxidative phosphorylation, to limit ROS production. This hypothesis was supported by the observation that UCP3 knockout mouse muscle mitochondria produced more ROS than wild type mitochondria (41). Recently, it was shown in isolated rat skeletal muscle mitochondria that proton conductance was increased by superoxides and that this increase was fatty acid-dependent and inhibited by GDP (42). An extension of this observation in vivo, would mean that the price to pay for avoiding ROS accumulation is a stimulation of UCP3 activity and a decrease in the efficiency of aerobic ATP production.

The "fasting paradox" and the observation that an increase in fatty acids disposal up-regulates muscle UCP3 expression (32-34) suggested 2 further hypotheses. The first is that the UCP3 role would be to prevent fatty acid accumulation in the mitochondria matrix by mediating the outward translocation of fatty acids (43). This implies that UCP3, functioning as a fatty acid anion carrier, is an uncoupling protein. The second hypothesis postulates that UCP3 participates directly in fatty acid degradation and may be a member of the $\beta$-oxidation pathway $(44,33,34)$. It implies that UCP3 might paradoxically contribute to a net production of ATP. This latter theory is supported by recent observations of the regulatory effect of AMP kinase (AMPK) on UCP3. The activation of AMPK is a key event in the stimulation of fatty acid degradation and of glucose uptake by muscle contraction (45). It would function as a "fuel gauge" signaling an ATP deficit. Recently, skeletal muscle AMPK activation by physical exercise or by its specific activator 5'-amino-4-imidazolecarboxamide ribonucleoside (AICAR) was found to increase UCP3 expression (46).
Human skeletal muscle is a heterogeneous tissue comprising of type I (slow oxidative), type lla (fast oxidative glycolytic) and type IIx (fast-glycolytic) muscle fibers. Type II have a lower oxidative efficiency than type I muscle fibers, with the $\mathrm{P}: \mathrm{O}$ ratio found to be $18 \%$ lower in the former $(47,48)$. It has been observed that UCP3 protein content is expressed decrescendo in $\| x>|| a>\mid$ muscle fiber types in both healthy and diabetic subjects (49) as well as in endurance trained cyclists. The higher UCP3 protein content in type II than in type I fibers might, in part, be responsible for their observed lower phosphate oxygen $(\mathrm{P}: \mathrm{O})$ ratio of type II fibers.

In humans, UCP3 mRNA $(50,51)$ and protein levels (43) have been shown to be lower in endurance trained cyclists as compared to healthy control subjects. Additionally, we have recently observed that the UCP3 protein content is lower in all fiber types of endurance trained when compared to healthy individuals. The interpretation of these results, which imply the belief that UCP3 is an uncoupling protein, would be that the increase in the efficiency of muscle oxidative metabolism observed after endurance training should be partly a result of reduced UCP3 expression.

Patients suffering from chronic obstructive pulmonary disease (COPD) demonstrate an impairment in their muscle oxidative metabolism, muscle weakness and exercise intolerance (52). A decrease in the oxidative enzyme activities of citrate synthase and 3-hydroxyacyl coenzyme A dehydrogenase and an increase in cytochrome c oxidase activity have also been observed (53). COPD patients also demonstrate a reduction in the cross sectional area of type I and type lla muscle fibers indicating muscle atrophy (53). We have recently found that UCP3 mRNA expression is lower in muscle biopsies from COPD patients when compared to healthy age-matched controls. The lower UCP3 mRNA level in COPD patients may be a protective response to limit any further impairment in their oxidative capacity and muscle atrophy.

Human UCP3 genetic studies might help to elucidate the biological role of this protein in vivo. Such studies so far have shown only weak associations between some of the UCP3 variants and obesity traits. Recently, a new GA repeat microsatellite located in UCP3 gene intervening sequence 6 (GAIVS6) was analyzed in the Quebec family. Strong associations were observed between some alleles and the BMI and the percent body fat (54). Suggestive linkages were also found in the Heritage family between GAIVS6 and changes in fat mass and percent body fat after endurance training (55). These results showing associations between UCP3 and obesity or body composi- 
tion changes after exercise suggest a role for this protein in energy expenditure.

The question of the biological role of UCP3 is controversial. Four hypotheses which are not necessarily exclusive of each other are presently prevailing. Our data in human muscle and genetic studies support the idea that UCP3 is an uncoupling protein involved in energy expenditure. UCP3 exact function, however, remains to be defined. Meanwhile, UCP3 might still be a good candidate as a target for anti-obesity drugs.

\section{ACKNOWLEDGEMENTS}

Our research was supported by grants from the Office Fédéral du Sport Macolin, Fonds Eugene Rapin, the Fondation du Centenaire de la Société Suisse d'Assurances générales sur la vie humaine pour la santé publique et les recherches médicales, the Helen M. Schutt Trust, the Sir. Jules Thorn Charitable Overseas Trust and the Swiss National Science Foundation grant no 31-65431.01.

\section{REFERENCES}

1. Cannon B., Nedergaard J. Nonshivering thermogenesis and brown adipose tissue. In: Blatteis C.M. (Ed.), Physiology and pathophysiology of temperature regulation. World Scientific, Memphis, 1998, p. 63.

2. Rothwell N.J., Stock M.J. A role for brown adipose tissue in diet-induced thermogenesis. Nature 1979, 281: 31-35.

3. Cannon B., Nedergaard J. The biochemistry of an inefficient tissue: brown adipose tissue. Essays Biochem. 1985, 20: 110-164.

4. Enerback S., Jacobsson A., Simpson E.M. et al. Mice lacking mitochondrial uncoupling protein are cold-sensitive but not obese. Nature 1997, 387: 90-94.

5. Cunningham S., Leslie P., Hopwood D. et al. The characterization and energetic potential of brown adipose tissue in man. Clin. Sci. (Lond.) 1985, 69: 343-348.

6. Lean M.E., James W.P., Jennings G., Trayhurn P. Brown adipose tissue uncoupling protein content in human infants, children and adults. Clin. Sci. (Lond.) 1986, 71: 291-297.

7. Emorine L.J., Marullo S., Briend-Sutren M.M. et al. Molecular characterization of the human beta 3-adrenergic receptor. Science 1989, 245: 1118-1121.

8. Muzzin P., Revelli J.P., Kuhne F. et al. An adipose tissuespecific beta-adrenergic receptor. Molecular cloning and down-regulation in obesity. J. Biol. Chem. 1991, 266: 24053-24058.

9. Giacobino J.P. Beta 3-adrenoceptor: an update. Eur. J. Endocrinol. 1995, 132: 377-385.

10. Collins S., Daniel K.W., Rohlfs E.M., Ramkumar V., Taylor I.L., Gettys T.W. Impaired expression and functional activity of the beta 3 - and beta 1 - adrenergic receptors in adipose tissue of congenitally obese (C57BL/6J ob/ob) mice. Mol. Endocrinol. 1994, 8: 518-527.
11. Revelli J.P., Preitner F., Samec S. et al. Targeted gene disruption reveals a leptin-independent role for the mouse beta3-adrenoceptor in the regulation of body composition. J. Clin. Invest. 1997, 100: 1098-1106.

12. Cousin B., Bascands-Viguerie N., Kassis N. et al. Cellular changes during cold acclimatation in adipose tissues. J. Cell. Physiol. 1996, 167: 285-289.

13. Collins S., Daniel K.W., Petro A.E., Surwit R.S. Strain-specific response to beta 3-adrenergic receptor agonist treatment of diet-induced obesity in mice. Endocrinology 1997 , 138: 405-413.

14. Ghorbani M., Claus T.H., Himms-Hagen J. Hypertrophy of brown adipocytes in brown and white adipose tissues and reversal of diet-induced obesity in rats treated with a beta3- adrenoceptor agonist. Biochem. Pharmacol. 1997, 54: 121-131.

15. Ghorbani M., Himms-Hagen J. Appearance of brown adipocytes in white adipose tissue during CL 316,243-induced reversal of obesity and diabetes in Zucker fa/fa rats. Int. J. Obes. Relat. Metab. Disord. 1997, 21: 465-475.

16. Guerra C., Koza R.A., Yamashita H., Walsh K., Kozak L.P. Emergence of brown adipocytes in white fat in mice is under genetic control. Effects on body weight and adiposity. J. Clin. Invest. 1998, 102: 412-420.

17. Himms-Hagen J., Melnyk A., Zingaretti M.C., Ceresi E., Barbatelli G., Cinti S. Multilocular fat cells in WAT of CL316243-treated rats derive directly from white adipocytes. Am. J. Physiol. Cell Physiol. 2000, 279: C670-C681.

18. Deng C., Paoloni-Giacobino A., Kuehne F. et al. Respective degree of expression of beta 1-, beta 2- and beta 3adrenoceptors in human brown and white adipose tissues. Br. J. Pharmacol. 1996, 118: 929-934.

19. Hoffstedt J., Lonnqvist F., Shimizu M., Blaak E., Arner P. Effects of several putative beta 3 -adrenoceptor agonists on lipolysis in human omental adipocytes. Int. J. Obes. Relat. Metab. Disord. 1996, 20: 428-434.

20. Tavernier G., Barbe P., Galitzky J. et al. Expression of beta3-adrenoceptors with low lipolytic action in human subcutaneous white adipocytes. J. Lipid Res. 1996, 37: 87-97.

21. Konkar A.A., Zhai Y., Granneman J.G. Beta1-adrenergic receptors mediate beta3-adrenergic-independent effects of CGP 12177 in brown adipose tissue. Mol. Pharmacol. 2000, 57: 252-258.

22. Sennitt M.V., Kaumann A.J., Molenaar P. et al. The contribution of classical (beta1/2-) and atypical beta- adrenoceptors to the stimulation of human white adipocyte lipolysis and right atrial appendage contraction by novel beta3adrenoceptor agonists of differing selectivities. J. Pharmacol. Exp. Ther. 1998, 285: 1084-1095.

23. Clement K., Vaisse C., Manning B.S. et al. Genetic variation in the beta 3-adrenergic receptor and an increased capacity to gain weight in patients with morbid obesity. N. Engl. J. Med. 1995, 333: 352-354.

24. Walston J., Silver K., Bogardus C. et al. Time of onset of non-insulin-dependent diabetes mellitus and genetic variation in the beta 3-adrenergic-receptor gene. N. Engl. J. Med. 1995, 333: 343-347. 
25. Widen E., Lehto M., Kanninen T., Walston J., Shuldiner A.R., Groop L.C. Association of a polymorphism in the beta 3-adrenergic-receptor gene with features of the insulin resistance syndrome in Finns. N. Engl. J. Med. 1995, 333: 348-351.

26. Shuldiner A.R., Sabra M. Trp64Arg beta3-adrenoceptor: when does a candidate gene become a disease-susceptibility gene? Obes. Res. 2001, 9: 806-809.

27. Collins S., Kunn C.M., Petro A.E., Swick A.G., Chrunyk B.A., Surwit R.S. Role of leptin in fat regulation. Nature 1996, 380: 677.

28. Scarpace P.J., Matheny M., Pollock B.H., Tumer N. Leptin increases uncoupling protein expression and energy expenditure. Am. J. Physiol. 1997, 273: E226-E230.

29. Satoh N., Ogawa Y., Katsuura G. et al. Sympathetic activation of leptin via the ventromedial hypothalamus: leptin-induced increase in catecholamine secretion. Diabetes 1999, 48: 1787-1793.

30. Boss O., Samec S., Paoloni-Giacobino A. et al. Uncoupling protein-3: a new member of the mitochondrial carrier family with tissue-specific expression. FEBS Lett. 1997, 408: 39-42.

31. Fleury C., Neverova M., Collins S. et al. Uncoupling protein-2: a novel gene linked to obesity and hyperinsulinemia. Nat. Genet. 1997, 15: 269-272.

32. Boss O., Muzzin P., Giacobino J.P. The uncoupling proteins, a review. Eur. J. Endocrinol. 1998, 139: 1-9.

33. Muzzin P., Boss O., Giacobino J.P. Uncoupling protein 3: its possible biological role and mode of regulation in rodents and humans. J. Bioenerg. Biomembr. 1999, 31: 467-473.

34. Boss O., Hagen T., Lowell B.B. Uncoupling proteins 2 and 3: potential regulators of mitochondrial energy metabolism. Diabetes 2000, 49: 143-156.

35. Echtay K.S., Winkler E., Frischmuth K., Klingenberg M. Uncoupling proteins 2 and 3 are highly active $\mathrm{H}(+)$ transporters and highly nucleotide sensitive when activated by coenzyme Q (ubiquinone). Proc. Natl. Acad. Sci. USA 2001, 98: 1416-1421.

36. Harper J.A., Stuart J.A., Jakobsons M.B. et al. Artifactual uncoupling by uncoupling protein 3 in yeast mitochondria at the concentrations found in mouse and rat skeletal-muscle mitochondria. Biochem. J. 2002, 361: 49-56.

37. Boss O., Samec S., Kuhne F. et al. Uncoupling protein-3 expression in rodent skeletal muscle is modulated by food intake but not by changes in environmental temperature. J. Biol. Chem. 1998, 273: 5-8.

38. Clapham J.C., Arch J.R., Chapman H. et al. Mice overexpressing human uncoupling protein-3 in skeletal muscle are hyperphagic and lean. Nature 2000, 406: 415-418.

39. Cadenas S., Echtay K.S., Harper J.A. et al. The basal proton conductance of skeletal muscle mitochondria from transgenic mice overexpressing or lacking uncoupling protein-3. J. Biol. Chem. 2002, 277: 2773-2778.

40. Skulachev V.P. Uncoupling: new approaches to an old problem of bioenergetics. Biochim. Biophys. Acta 1998, 1363: $100-124$
41. Vidal-Puig A.J., Grujic D., Zhang C.Y. et al. Energy metabolism in uncoupling protein 3 gene knockout mice. J. Biol. Chem. 2000, 275: 16258-16266.

42. Echtay K.S., Roussel D., St-Pierre J. et al. Superoxide activates mitochondrial uncoupling proteins. Nature 2002, 415: 96-99.

43. Schrauwen P., Saris W.H., Hesselink M.K. An alternative function for human uncoupling protein 3: protection of mitochondria against accumulation of nonesterified fatty acids inside the mitochondrial matrix. FASEB. J. 2001, 15: 2497-2502.

44. Samec S., Seydoux J., Dulloo A.G. Role of UCP homologues in skeletal muscles and brown adipose tissue: mediators of thermogenesis or regulators of lipids as fuel substrate? FASEB. J. 1998, 12: 715-724.

45. Hayashi T., Hirshman M.F., Kurth E.J., Winder W.W., Goodyear L.J. Evidence for 5' AMP-activated protein kinase mediation of the effect of muscle contraction on glucose transport. Diabetes 1998, 47: 1369-1373.

46. Zhou M., Lin B.Z., Coughlin S., Vallega G., Pilch P.F. UCP3 expression in skeletal muscle: effects of exercise, hypoxia, and AMP-activated protein kinase. Am. J. Physiol. Endocrinol. Metab. 2000, 279: E622-E629.

47. Crow M.T., Kushmerick M.J. Chemical energetics of slowand fast-twitch muscles of the mouse. J. Gen. Physiol. 1982, 79: 147-166.

48. Kushmerick M.J., Meyer R.A., Brown T.R. Regulation of oxygen consumption in fast- and slow-twitch muscle. Am. J. Physiol. 1992, 263: C598-C606.

49. Hesselink M.K., Keizer H.A., Borghouts L.B. et al. Protein expression of UCP3 differs between human type 1, type 2a, and type 2b fibers. FASEB. J. 2001, 15: 1071-1073.

50. Schrauwen P., Troost F.J., Xia J., Ravussin E., Saris W.H. Skeletal muscle UCP2 and UCP3 expression in trained and untrained male subjects. Int. J. Obes. Relat. Metab. Disord. 1999, 23: 966-972.

51. Russell A., Wadley G., Snow R. et al. Slow component of $\mathrm{VO}_{2}$ kinetics: the effect of training status, fibre type, UCP3 mRNA and citrate synthase activity. Int. J. Obes. Relat. Metab. Disord. 2002, 26: 157-164.

52. Sala E., Roca J., Marrades R.M. et al. Effects of endurance training on skeletal muscle bioenergetics in chronic obstructive pulmonary disease. Am. J. Respir. Crit. Care Med. 1999, 159: 1726-1734.

53. Mador M.J., Bozkanat E. Skeletal muscle dysfunction in chronic obstructive pulmonary disease. Respir. Res. 2001, 2: 216-224.

54. Lanouette C.M., Giacobino J.P., Perusse L. et al. Association between uncoupling protein 3 gene and obesity-related phenotypes in the Quebec Family Study. Mol. Med. 2001, 7: 433-441.

55. Lanouette C.M., Chagnon Y.C., Rice T. et al. Uncoupling protein 3 gene is associated with body composition changes with training in HERITAGE study. J. Appl. Physiol. 2002, 92: 1111-1118. 